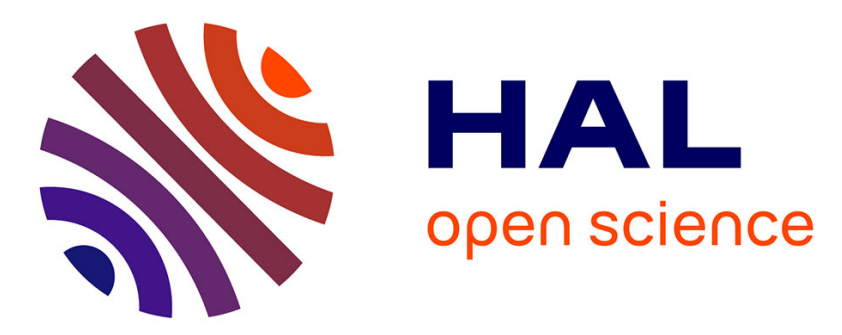

\title{
Time scale considerations on the relaxation of electronic and vibrational energy distributions in a nitrogen afterglow
}

\author{
M. Capitelli, C. Gorse, André Ricard
}

\section{- To cite this version:}

M. Capitelli, C. Gorse, André Ricard. Time scale considerations on the relaxation of electronic and vibrational energy distributions in a nitrogen afterglow. Journal de Physique Lettres, 1983, 44 (7), pp.251-256. 10.1051/jphyslet:01983004407025100 . jpa-00232189

HAL Id: jpa-00232189

https://hal.science/jpa-00232189

Submitted on 1 Jan 1983

HAL is a multi-disciplinary open access archive for the deposit and dissemination of scientific research documents, whether they are published or not. The documents may come from teaching and research institutions in France or abroad, or from public or private research centers.
L'archive ouverte pluridisciplinaire HAL, est destinée au dépôt et à la diffusion de documents scientifiques de niveau recherche, publiés ou non, émanant des établissements d'enseignement et de recherche français ou étrangers, des laboratoires publics ou privés. 
Classification

Physics Abstracts

52.20

\title{
Time scale considerations on the relaxation of electronic and vibrational energy distributions in a nitrogen afterglow $\left({ }^{+}\right)$
}

\author{
M. Capitelli, C. Gorse and A. Ricard (*) \\ Centro di Studio per la Chimica dei Plasmi del C.N.R., Dipartimento di Chimica, \\ Via Amendola 173, 70100 Bari, Italy \\ $\left({ }^{*}\right)$ Laboratoire de Physique des Gaz et des Plasmas, Université Paris-Sud, 91405 Orsay, France
}

(Reçu le 14 septembre 1982, révisé le 7 février 1983, accepté le 15 février 1983)

\begin{abstract}
Résumé. - La relaxation de la fonction de distribution en énergie des électrons (edf) dans une " postdécharge " d'azote vibrationnellement excité a été analysée à partir des temps caractéristiques nécessaires pour réaliser et maintenir un état quasi-stationnaire de " edf ». Ces temps caractéristiques sont ensuite comparés aux temps de pertes des électrons par recombinaison dissociative et par diffusion sur les parois du tube, qui sont les plus significatifs. Les résultats du calcul montrent que les collisions électroniques sur l'azote vibrationnellement excité peuvent créer un état quasi-stationnaire de " edf » dans des temps de $10^{-7}$ à $10^{-6} \mathrm{~s}(p=5$ torr, $T=500 \mathrm{~K})$. Cet état quasi-stationnaire est caractérisé par une forte corrélation entre distribution vibrationnelle et énergie moyenne des électrons, et peut durer plusieurs $10^{-3} \mathrm{~s}$ jusqu'au temps où la densité électronique est devenue trop faible par recombinaison et diffusion.
\end{abstract}

Finalement, on commente certains résultats expérimentaux publiés précédemment.

\begin{abstract}
The relaxation of the electron energy distribution function (edf) in vibrationally excited $\mathrm{N}_{2}$ post discharges has been analysed by discussing the characteristic times necessary for " edf " to achieve and maintain a quasistationary state and by comparing these times with other important times corresponding to electron losses by dissociative recombination and diffusion to the tube wall. The calculated results show that the vibrational collisions can create a quasistationary "edf " in times of $10^{-7}-10^{-6} \mathrm{~s}(p=5$ torr, $T=500 \mathrm{~K})$. This quasistationary state is characterized by a strong correlation between vibrational distribution and mean electron energy. It can last up to several $10^{-3} \mathrm{~s}$ till the electron density becomes too small as a result of recombination and diffusion.
\end{abstract}

Comments of some earlier experimental results are finally given.

\section{Introduction.}

We have recently shown [1] that the electron energy distribution function (edf) relaxes in $\mathrm{N}_{2}$ post discharges in different ways according to the presence or absence of vibrationally excited molecules (vem). In particular the presence of « vem » is such as to establish a quasistationary

$\left({ }^{+}\right)$Work supported in part by the «Progetto Finalizzato Laser di Potenza del C.N.R.». 
" edf " in a post discharge as a result of the compensation between vibrational energy losses and superelastic energy gains. Such a behaviour disappears in the absence of " vem » as shown in $[1,2]$.

Questions arise i) about the time $\tau_{\mathrm{a}}$ necessary for "edf» to achieve a quasistationary state, ii) about the duration $\tau_{d}$ of this quasistationary state. The purpose of this letter is to answer these questions.

\section{2: Creation and duration of the « edf » quasistationary state.}

The calculations reported in [1] showed that the "edf " in $\mathrm{N}_{2}^{-}$post discharges reached quasistationary values in times of about $\tau_{\mathrm{a}} \sim 10^{-7} \mathrm{~s}$ to $10^{-6} \mathrm{~s}$ according to the initial vibrational distribution in the discharge. The shorter time corresponds to a vibrational distribution characterized by a $0-1$ vibrational temperature $\theta_{1}=8540 \mathrm{~K}$ while the longer time refers to $\theta_{1}=3400 \mathrm{~K}$ (in all cases the pressure was 5 torr and the gas temperature $500 \mathrm{~K}$ ).

These times were obtained by solving the time dependent Boltzmann equation without the electric field term [1] :

$$
\frac{\partial n(\varepsilon, t)}{\partial t}=-\frac{\partial J_{\text {el. }}}{\partial \varepsilon}+\text { In. }+ \text { Sup. }+ \text { Rot. }
$$

where $\varepsilon$ is the electron energy, and $\partial J_{\mathrm{el}} / \partial \varepsilon$, In., Sup. and Rot. is the flux of electrons along the energy axis carried out by elastic, inelastic vibrational, superelastic vibrational, and rotational collisions respectively.

Equation (1) neglects the term due to electron-electron collisions which usually becomes important at higher ionization degrees $\left(>10^{-4}\right)$. This term should probably be included also at lower ionization degrees when the electron temperature achieves very small values.

To understand the temporal evolution of $n(\varepsilon, t)$ (see ref. [1]), we have reported in table I the power dissipated by the electrons in the different channels for the case $\theta_{1}=3400 \mathrm{~K}$. These quantities have been obtained by integrating the different losses (or gain) over the actual " edf ». We can see that during the relaxation the dominant terms are due to the inelastic vibrational losses which balance the superelastic vibrational gains in a time $\tau_{\mathrm{a}}$ of the order of $10^{-7} \mathrm{~s}$. These times are strictly correlated to the processes :

$$
\mathrm{e}+\mathrm{N}_{2}(V) \rightleftarrows \mathrm{e}+\mathrm{N}_{2}(W)
$$

where $V, W$ are vibrational quantum numbers.

Table I. - Power losses (el. $\equiv$ elastic, rot. $\equiv$ rotational, in. $\equiv$ inelastic vibrational) and power gain (sup. 三 superelastic vibrational) in $\mathrm{N}_{2}$ decaying plasma at different times ( $p=5$ torr, $\left.\theta_{1}=3400 \mathrm{~K}, T_{\mathrm{g}}=500 \mathrm{~K}\right) .(-5)=10^{-5}$, powers in $\operatorname{erg~s}^{-1}$.

\begin{tabular}{|ccccc|}
\hline$t(\mathrm{~s})$ & $E_{\text {el. }}$ & $E_{\text {rot. }}$ & $E_{\text {in. }}$ & $E_{\text {sup. }}$ \\
\hline $5.0(-9)$ & $6.12(-7)$ & $4.67(-7)$ & $2.97(-4)$ & $2.83(-5)$ \\
$1.0(-8)$ & $5.77(-7)$ & $4.61(-7)$ & $2.73(-4)$ & $2.67(-4)$ \\
$1.0(-7)$ & $4.39(-7)$ & $4.27(-7)$ & $1.93(-4)$ & $1.92(-4)$ \\
$1.3(-6)$ & $2.27(-7)$ & $3.25(-7)$ & $8.64(-5)$ & $8.67(-5)$ \\
$1.0(-5)$ & $1.53(-7)$ & $2.28(-7)$ & $5.92(-5)$ & $5.97(-5)$ \\
$1.1(-4)$ & $1.54(-7)$ & $2.29(-7)$ & $5.93(-5)$ & $5.97(-5)$ \\
$1.1(-3)$ & $1.54(-7)$ & $2.30(-7)$ & $5.93(-5)$ & $5.97(-5)$ \\
$1.1(-2)$ & $1.54(-7)$ & $2.30(-7)$ & $5.93(-5)$ & $5.97(-5)$ \\
\hline
\end{tabular}


Moreover we can note the elastic and rotational losses are negligible with respect to the vibrational energy losses, thus confirming that processes $(a)$ are responsible for the creation of a quasistationary " edf ». Further we see from table I that, for a fixed $N_{v}$ distribution at $\theta_{1}$, this quasistationary state can last up to several milliseconds.

As a consequence the quasistationary state described in [1] and confirmed by the present calculations to longer times will change only as the vibrational distribution changes in time.

This distribution in the $\mathrm{N}_{2}$ post discharges changes according to $\mathrm{V}-\mathrm{V}$ (vibration-vibration) relaxation processes :

$$
\mathrm{N}_{2}(V)+\mathrm{N}_{2}(W) \rightleftarrows \mathrm{N}_{2}(V-1)+\mathrm{N}_{2}(W+1) .
$$

A typical relaxation time for this process can be calculated [3] from :

$$
\tau_{\mathrm{Vv}}=\frac{1}{N_{\mathrm{T}} P_{1,0}^{0,1}}
$$

with $N_{\mathrm{T}}$ total $\mathrm{N}_{2}$ density and $P_{1,0}^{0,1}$ rate coefficient for $V=1, W=0$ levels. Particularly, one has $\tau_{\mathrm{vv}} \simeq 7 \times 10^{-4} \mathrm{~s}$ at $p=5$ torr, $T_{\mathrm{g}}=500 \mathrm{~K}$.

Of course $N_{\mathrm{v}}$ can change also from processes $(a)$ with a relaxation time $\tau_{\mathrm{ev}}$ given by :

$$
\tau_{\mathrm{eV}}=\frac{1}{n_{\mathrm{e}} K_{1,0}^{\mathrm{e}}},
$$

where $n_{\mathrm{e}}$ is the total electron density and $K_{1,0}^{\mathrm{e}}$ is the rate coefficient for the $(1,0)$ vibrational transition by electron collisions. For $n_{\mathrm{e}}=10^{11} \mathrm{~cm}^{-3}, \tau_{\mathrm{ev}}=10^{-3} \mathrm{~s}\left(\theta_{1}=8540 \mathrm{~K}\right)$ and $10^{-2} \mathrm{~s}$ $\left(\theta_{1}=3400^{\prime} \mathrm{K}\right)$ [1]. This means that electrons in the post discharge and in the presence of "vem " will conserve averaged energies $\bar{u}$ for times $\tau_{d}$ of the order of $V-V$ and $e-V$ relaxation times. The averaged energies $\bar{u}$ are then expected to be correlated to some extent with the vibrational energy of the molecular gas [4]. This point is made clear by looking at figure 1 where $\bar{u}$ calculated from " edf " is reported as a function of time in the $\mathrm{N}_{2}$ post discharge. We can see that starting with an " edf " consistent with $N_{\mathrm{v}}$ at $\theta_{1}=8540 \mathrm{~K}$ we arrive, when superelastic collisions are taken into account at a stationary value, in the post discharge of $\bar{u}=1.5 \mathrm{eV}$ ( $T_{\mathrm{e}} »=\frac{2}{3} \bar{u}=$ $11600 \mathrm{~K}$ ). While starting with an « edf » consistent with $\theta_{1}=3400 \mathrm{~K}$ we arrive at $\bar{u} \cong 0.4 \mathrm{eV}$ ( $\left(T_{\mathrm{e}} »=3100 \mathrm{~K}\right.$ ). This points out the good correlation between $\theta_{1}$ and $\bar{u}$ in the post discharge.

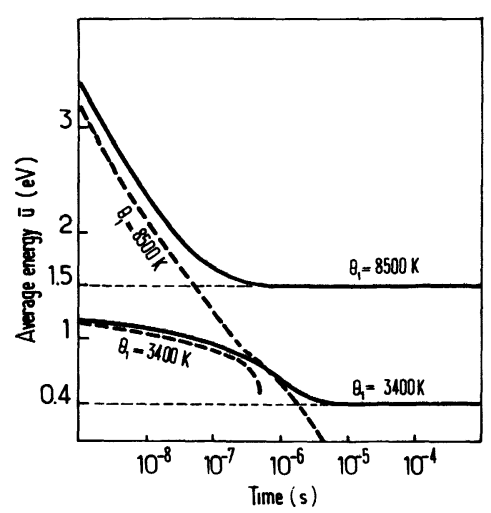

Fig. 1. - Relaxation of the electron average energy $\bar{u}$ in a $N_{2}$ post discharge for two $\theta_{1}$ values. Results of the calculations with and without superelastic vibrational collisions are in full and dashed lines. 
We can expect that, over times of the order of $10^{-3} \mathrm{~s}$, when appreciable variations in the vibrational distribution occur as a result of $\mathrm{V}-\mathrm{V}$ and $\mathrm{e}-\mathrm{V}$ processes, $\bar{u}$ will adapt itself to the new values. Over these times, however, the decoupling of the Boltzmann equation for the electrons from the system of vibrational master equations operated in [1] and in the present work does not any more fulfil so that a self-consistent solution of the Boltzmann equation and of the system of vibrational master equations must be carried out.

\section{Characteristic tumes of recombination and diffusion of electrons.}

Further complications arise at longer times because electrons are lost by volume recombination and diffusion to the tube walls. Let us examine the characteristic times associated to these loss terms.

The electron recombination is a dissociative process following :

$$
\mathrm{e}+\mathrm{N}_{2}^{+} \stackrel{k_{\boldsymbol{x}}}{\rightarrow} \mathrm{N}+\mathrm{N}
$$

where $k_{\mathrm{r}}$ is the recombination coefficient.

It follows that the recombination time is

$$
\tau_{\text {rec }}=\left(n_{\mathrm{e}} k_{\mathrm{r}}\right)^{-1} \text {. }
$$

For the typical conditions studied in [1] $(p=5$ torr, $R=1 \mathrm{~cm})$ the electron diffusion to the tube wall follows the ambipolar regime and the corresponding characteristic time can be written as :

$$
\tau_{\text {diff }}=\left(D_{\mathrm{a}} / \Lambda^{2}\right)^{-1}
$$

where $D_{\mathrm{a}}$ is the ambipolar diffusion coefficient and $\Lambda=R / 2.4$ is the characteristic diffusion length. We obtain $\tau_{\text {rec }} \cong 3 \times 10^{-5} \mathrm{~s}$ and $\tau_{\text {diff }} \cong 10^{-2} \mathrm{~s}\left(n_{\mathrm{e}}=10^{11} \mathrm{~cm}^{-3}, k_{\mathrm{r}}=3 \times 10^{-7} \mathrm{~cm}^{3} \mathrm{~s}^{-1}\right.$ [5] and $D_{\mathrm{a}} p \sim 10^{2} \mathrm{~cm}^{2} \mathrm{~s}^{-1}$ torr) from the $\mathrm{N}_{2}^{+}$mobility reported in [6]. It should be noted however that the above $k_{\mathrm{r}}$ and $D_{\mathrm{a}} p$ values have been obtained for electrons thermalized at $T_{\mathrm{e}}=300 \mathrm{~K}$. This is true in the absence of superelastic vibrational collisions as can be appreciated from the dashed curves of figure 1 . We see that $\bar{u}$ calculated in the absence of « vem " falls rapidly. In the presence of "vem ", as already discussed, $\bar{u}$ goes to 1.5 or $0.4 \mathrm{eV}\left(\theta_{1}=8500 \mathrm{~K}\right.$ or $\left.3400 \mathrm{~K}\right)$ so that we must calculate $\tau_{\text {rec }}$ and $\tau_{\text {diff }}$ at these electron temperatures.

As $k_{\mathrm{r}} \sim T_{\mathrm{e}}^{-1 / 3}$ [5], $\tau_{\mathrm{rec}}$ increases with increasing electron temperature (Eq. 4), the opposite being true for the diffusion time (Eq. 5), since $D_{\mathrm{a}}=\mu_{\mathrm{i}} \frac{k T_{\mathrm{e}}}{e}\left(\mu_{\mathrm{i}}\right.$ ionic mobility) [6]. This brings $\tau_{\text {rec }}$ and $\tau_{\text {diff }}$ in the order of $10^{-4}-10^{-3} \mathrm{~s}$ for the conditions studied in the present work.

Thus, at these times, we can no longer disregard these electron loss processes. At still longer times we must insert a new source of electrons given by the pooling reaction [7] :

$$
\mathrm{N}_{2}(V)+\mathrm{N}_{2}(W)-\left[\begin{array}{l}
\mathrm{e}+\mathrm{N}_{4}^{+} \\
\mathrm{e}+\mathrm{N}_{2}^{+}+\mathrm{N}_{2},
\end{array}\right.
$$

and probably by other reactions involving metastable states.

All these considerations allow us to distinguish two regimes in the relaxation of "edf " of vibrationally excited $\mathrm{N}_{2}$ post discharges. A first regime which approximately lasts up to $10^{-4} \mathrm{~s}$ in our conditions, in which the averaged electron energy $\bar{u}$ achieves and maintains values approximately equal to the vibrational temperature of $\mathrm{N}_{2}$ in the discharge. A second regime in the $10^{-4}-10^{-2} \mathrm{~s}$ range in which $\bar{u}$ can change according to the change of the $\mathrm{N}_{2}$ vibrational distri- 
bution. This second regime can be further complicated by the generation of new electrons by pooling reactions of « vem » which may alter the " edf " relaxation.

It should be noted that recombination and diffusion processes destroy electrons without altering the " edf " only if averaged coefficients are used. On the contrary these processes should also change « edf» if use is made of coefficients depending on the electron energy $(\varepsilon)$.

\section{Comments on earlier experimental results.}

Some earlier experimental works [8-10] seem to indicate the lines expressed in this work as well as in [1]. The experimental work of Formato and Gilardini [8] appears in fact as an indication of the first regime. These authors, studying the $\mathrm{N}_{2}$ post discharge at pressure about 1 torr, found that electron temperatures up to $4000 \mathrm{~K}$ could survive in post discharges for times of $(1-2) \times 10^{-4} \mathrm{~s}$. This experimental result, which Formato and Gilardini explained by the formation of energetic new electrons coming from collisions between metastable nitrogen molecules, can easily be explained by our calculations provided one assumes (realistically) that, at the end of the $\mathrm{N}_{2}$ glow discharge, $\theta_{1}$ achieves values $\leqslant 4000 \mathrm{~K}$.

An electron temperature of about (6-8) $\times 10^{3} \mathrm{~K}$ constant during several $10^{-3} \mathrm{~s}$ in a $\mathrm{N}_{2}$ post discharge at 1.75 torr was found by Brömer and Döbler [9]. This value is between the electron temperatures found in our calculations. The work of Brömer and Döbler apparently does not distinguish between the two regimes discussed in the present study.

Chen and Goodings [10] studying the " pink afterglow » of a $\mathrm{N}_{2}$ flowing post discharge at 9 torr obtained electron temperatures which reached a maximum value of $4.5 \mathrm{eV}(t=5 \mathrm{~ms})$ starting from $2 \mathrm{eV}(1 \mathrm{~ms})$ and ending at $1 \mathrm{eV}(12 \mathrm{~ms})$. The electron temperature measured by probes in [10] seems too high as compared with our calculations. It should be noted however that the electron temperature concept only makes sense for a Maxwellian " edf ». This is not the case as shown in [1] and discussed by Chen and Goodings themselves. It should be better to compare our averaged energies $\bar{u}$ with the $k T_{\mathrm{e}}$ values reported in [10]. There is a satisfactory agreement at the beginning $(1 \mathrm{~ms})$ and at the end $(12 \mathrm{~ms})$ of the pink afterglow, with the present $\bar{u}$ value found at $\theta_{1}=8500 \mathrm{~K}$ (cf. Fig. 1).

However our calculations cannot justify the maximum value of $k T_{\mathrm{e}}=4.5 \mathrm{eV}$ experimentally found in [10]. In this case we must admit the creation of new energetic electrons by bimolecular reactions involving vibrationally excited molecules and/or metastable electronic state as well as superelastic collisions involving cold electrons and metastable $\mathbf{N}_{2}$ molecules.

It should be stressed again that the comparison between experimental and theoretical results made in this section is only qualitative since the "vibrational temperatures " under the different experimental conditions are not reported.

\section{Conclusion.}

The present results as well as those reported in reference [1] show the importance of a strong coupling between electron and vibrational distribution functions at the exit of a nitrogen discharge. They should stimulate an extensive experimental study on the relaxation of these two distribution functions in nitrogen afterglows. Electrostatic probe technics can be used for « electron temperature $T_{e}$ " [10] and lasers [11], electron beams [12] or metastable atoms [13], excited fluorescence for " vibrational temperature $\theta_{1}$ " (see also [14] for C.A.R.S. technics in $\mathrm{H}_{2}$ ). The knowledge of these temperatures is in fact of primary importance for understanding the coupling between vibrational and electronic energies. Further experimental works should therefore measure at the time $" T_{\mathrm{e}}$ " and $" \theta_{1} \|$.

The theory, on the other hand, can be improved :

i) by coupling the Boltzmann equation of electrons with the system of vibrationally master equations ; 
ii) by including a continuity equation for the electron density which takes into account the recombination, diffusion and creation of new electrons by bimolecular reactions; and

iii) by including in the Boltzmann equation other heating processes of electrons in addition to the superelastic vibrational collisions involving probably electronic metastable $\mathrm{N}_{2}$ molecules.

\section{References}

[1] Capitelli, M., Gorse, C. and Ricard, A., J. Physique Lett. 42 (1981) L-469.

[2] Winkler, R. and Wilhelm, J., Beitr. Plasma Phys. 21 (1981) 163.

[3] Capitelli, M., Gorse, C. and RiCard, A., J. Physique Lett. 42 (1981) L-185.

[4] Hurle, J. R., J. Chem. Phys. 41 (1964) 3592.

[5] BIONDI, M. A., Can. J. Chem. 47 (1969) 1711.

[6] Hasted, J. B., Physics of Atomic Collisions (Butterworth) 1972.

[7] Capitelli, M., Gorse, C. and Ricard, A., J. Physique Lett. 43 (1982) L-417.

[8] Formato, D. and Gilardini, A., IV ICPIG (1959) Uppsala.

[9] BRöMer, H. H. and Dö̈ler, F., Z. Phys. 185 (1965) 278.

[10] Chen, S. L. and Goodings, J. M., J. Chem. Phys. 50 (1969) 4335.

[11] Denisov, V. N. et al., JETP Lett. 27 (1978) 645.

[12] Camprell, D. H. and Muntz, E. P., J. Chem. Phys. 72 (1980) 1487.

[13] Jolly, J., Touzeau, M. and Ricard, A., J. Phys. B 14 (1981) 473.

[14] Pealat, M. et al., ISPC-5 (1981) 476, Edinburgh. 